\title{
SISTEM INFOMASI PENJUALAN OLD BOOK SECARA ONLINE PADA TOKO RHENY BOOK JAKARTA
}

\author{
Eka Satryawati ${ }^{1}$ \\ Program Studi Sistem Informasi \\ Universitas Mohammad Husni Thamrin \\ ekathufail@gmail.com
}

\author{
Eka Nugraha ${ }^{2}$ \\ Program Studi Manajemen Informatika \\ STMIK Nusa Mandiri \\ nugrahaexs@gmail.com
}

\begin{abstract}
ABSTRAK
Pembelajaran, dalam prakteknya tidak bisa dihindari dari penggunaan teknologi terutama Teknologi Informasi (TI). TI telah mampu memberikan kontribusi bagi penjual dan pembeli di dunia perdagangan. Pelanggan semakin dipermudah dalam melakukan pemesanan barang maupun transaksi. Tujuan dari penelitian terhadap toko Rheny book ini adalah untuk membangun penjualan berbasis web sebagai media transaksi yang sedang berkembang pada saat ini. Penelitian dilakukan dengan mengamati sistem secara langsung sehingga didapatkan hasil analisis mengenai kebutuhan sistem yang akan dibuat. Studi pustaka juga dilakukan untuk mencari sumber-sumber lain yang dapat menjadi dasar dan acuan dalam membuat sistem informasi e-commerce. Sistem informasi Penjualan Old Book secara Online ini dibuat dengan menggunakan bahasa pemrograman PHP dan MySQL database. Toko buku online Rheny book merupakan suatu bidang usaha yang melayani penjualan buku tua atau lama. Penjualan buku dilakukan dengan datang langsung ke toko maka dibuatlah website penjualan untuk menampilkan informasi buku yang ditawarkan oleh toko Rheny Book. Pelanggan dapat menjadi member dan melakukan pembelian buku secara online, dan terdapat pencarian data buku.
\end{abstract}

Kata Kunci : Sistem Informasi, PHP, E-commerce

\section{Pendahuluan}

Pada saat ini sistem penjualan produk melalui internet sedang berkembang pesat, banyak perusahaan yang memanfaatkan teknologi yang berbasis web sebagai suatu strategi perusahaan dalam menawarkan produk mereka kepada seluruh konsumen tanpa harus dibatasi oleh ruang dan waktu.

Mulai dari perusahaan besar hingga perusahaan kecil dan menengah menjadikan sistem penjualan secara online sebagai sarana promosi yang murah dan terjangkau. Produk yang ditawarkan oleh tiap situs - situs penjualan online sangat beragam

Penulisan karya ilmiah ini hanya membahas tentang sistem penjualan old book secara online seperti : pemesanan barang, pengecekan stok barang, proses transaksi pembayaran, proses pengiriman.

Pada proses bisnis penjualan di Rheny Book Store masih menggunakan Microsoft Excel 2007 dimana seorang pelanggan buku melakukan pesanan secara langsung dengan mendatangi Toko Rheny Book, dan admin toko melakukan pengecekan stok buku di database, bila stok buku tersedia, maka proses pesanan dapat diteruskan kemudian pelanggan melakukan pembayaran ke kasir dan menerima bukti pembayaran berupa struk pembayaran dan pelanggan mendapatkan buku yang telah di bayarnya. 


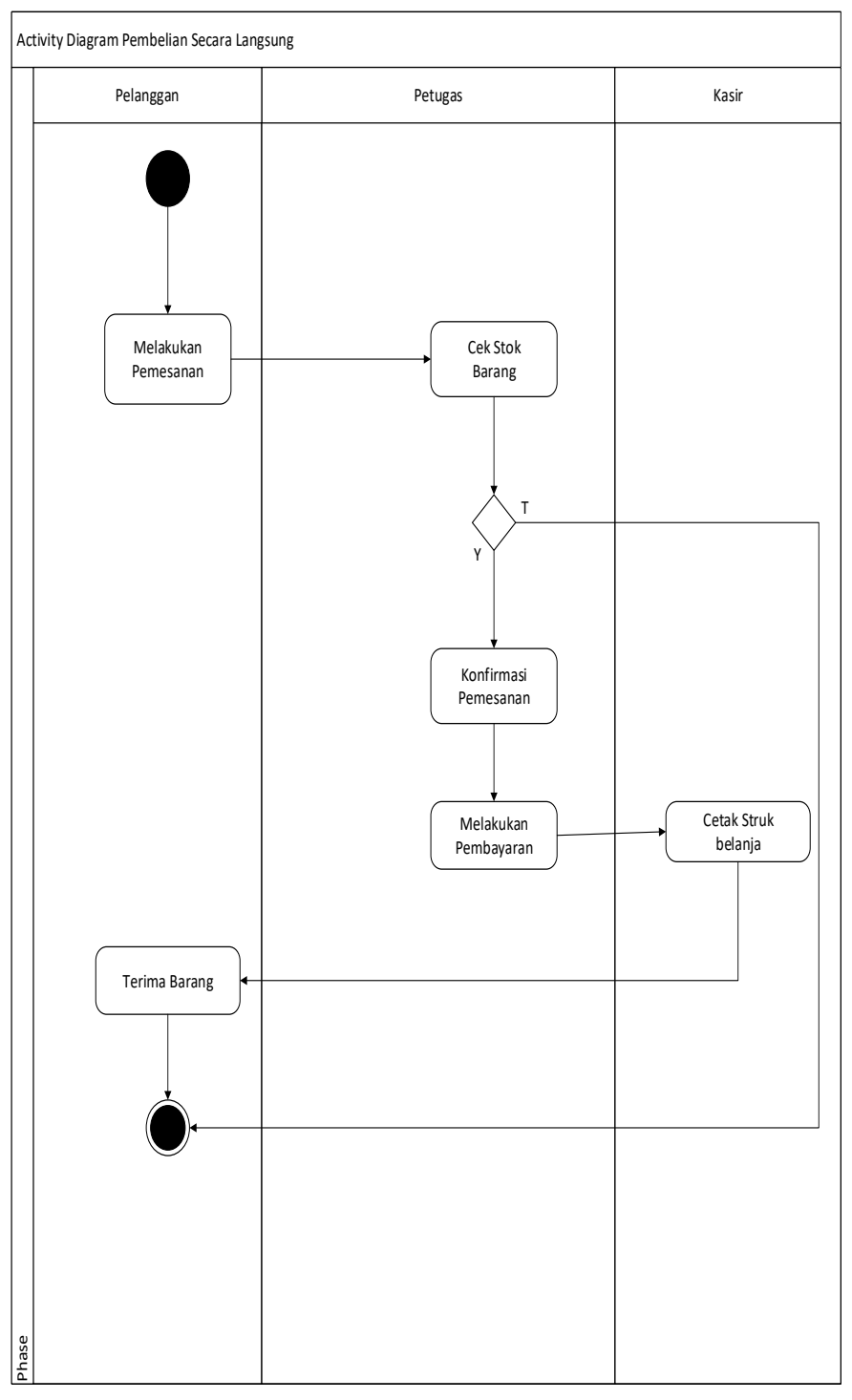

Gambar 1. Activity Diagram pelanggan melakukan pemesanan secara langsung

\section{METODE PENGEMBANGAN SISTEM}

Menurut Sommerville (2007:30), "tahapan utama dari waterfall model langsung mencerminkan aktifitas pengembangan dasar. Terdapat beberapa tahapan pada waterfall model, yaitu analisa kebutuhan, perancangan sistem dan perangkat lunak, implementasi dan pengujian unit". Berikut adalah penjelasan dari tahapan-tahapan tersebut :

Model pengembangan sistem yang penulis gunakan dalam penulisan skripsi ini antara lain:
A. Analisa Kebutuhan Software
Pada tahap ini penulis mempelajari dan memahami tentang permasalahan dan hal-hal yang berkaitan dengan sistem pengolahan data.

Setelah proses analisa kebutuhan software telah selesai dilakukan maka tahap berikutnya adalah melakukan tahap desain. Pada tahapan ini penulis melakukan perancangan sistem informasi penjualan buku secara online meliputi desain sistem menggunakan UML yang terdiri dari usecase diagram, activity diagram, component diagram dan deployment diagram.

\section{Code Generation}

Dalam membangun sistem informasi penjualan buku online ini penulis menggunakan kode pemrograman Hypertext Preprocessor (PHP), MySQL, Casecading Style Sheet (CSS) dan script Hypertext Markup Languge (HTML).

\section{Testing}

Setelah sistem telah selesai dibuat, maka akan dilakukan pengujian untuk menganalisa dan mengantisipasi kesalahan-kesalahan sistem yang mungkin terjadi.

\section{E. Support}

Berkaitan dengan pembuatan sistem informasi penjualan old book secara online ini, penulis telah mencoba memperhatikan, mempelajari dan memahami spesifikasi hardware serta software yang akan dipergunakan untuk mendukung berjalannya sistem ketika diimplementasikan. Adapun hardware yang digunakan penulis untuk membangun sistem informasi ini adalah komputer dengan spesifikasi Intel ${ }^{\circledR}$ Pentium ${ }^{\circledR}$ processor P6100 dan untuk pengembangnnya dapat menggunakan spesifikasi hardware yang lebih baik. Sedangkan untuk software, penulis menggunakan Microsoft Wondows 7 dan untuk pengembangan sistem dapat mengunakan software-software dengan versi terbaru.

\section{RANCANGAN SISTEM DAN PROGRAM}

Dalam melakukan proses pembelanjaan pelanggan dapat melakukannya dengan secara online atau datang langsung ke toko, admin akan menggunakan sistem informasi penjualan secara online, oleh karena itu dibutuhkan tampilan yang akan digunakan untuk berinteraksi antara pemakai dengan sistem informasi. Berikut ini spesifikasi kebutuhan (system requirement) dari sistem informasi penjualan old book secara online ini.

Kebutuhan pelanggan

A.1. Pelanggan Login menggunakan username dan password yang sudah terdaftar

A.2. Pelanggan dapat melakukan pemesanan tanpa melakukan login terlebih dahulu

\section{B. Desain}


A.3. Setelah pelanggan melakukan pemesan, pelanggan bisa langsung melakukan pengisian data untuk barang yang akan dikirim

A4. Pelanggan melakukan pembayaran sesuai dengan barang yang telah dipilihnya dan memilih metode pembayaran yang sudah tersedia.

A5. Pelanggan dapat mencetak bukti pembayaran berupa invoice pembayaran dan melakukan konfirmasi pembayaran.

Kebutuhan Admin

B1. Admin Dapat melakukan Login.

B2. Admin dapat mengelola data katagori

B3. Admin dapat mengelola data barang

B4. Admin dapat mengelola data pelanggan

B5. Admin dapat mengelola data pemesanan

B6. Admin dapat melihat konfirmasi

B7. Admin dapat membuat laporan penjualan

Activity Diagram Login Pelanggan Pada Halaman Admin

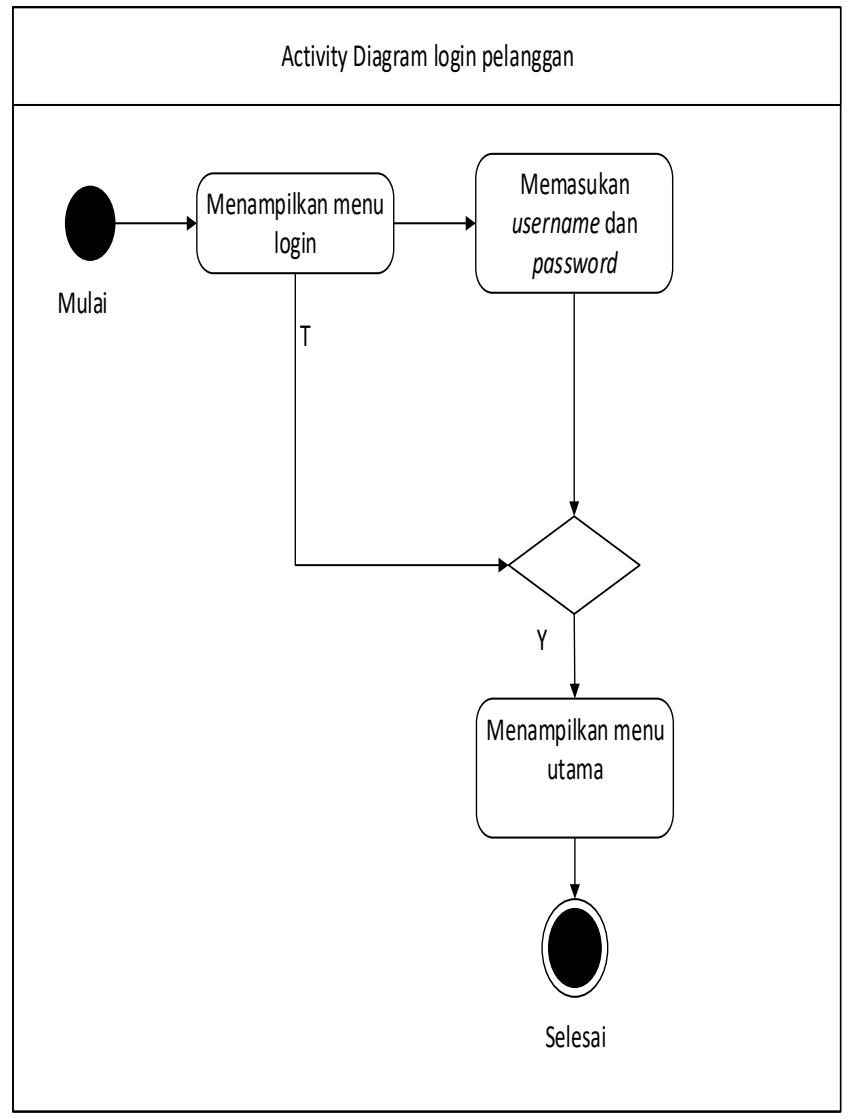

Gambar 2. Activity Diagram Login Pelanggan

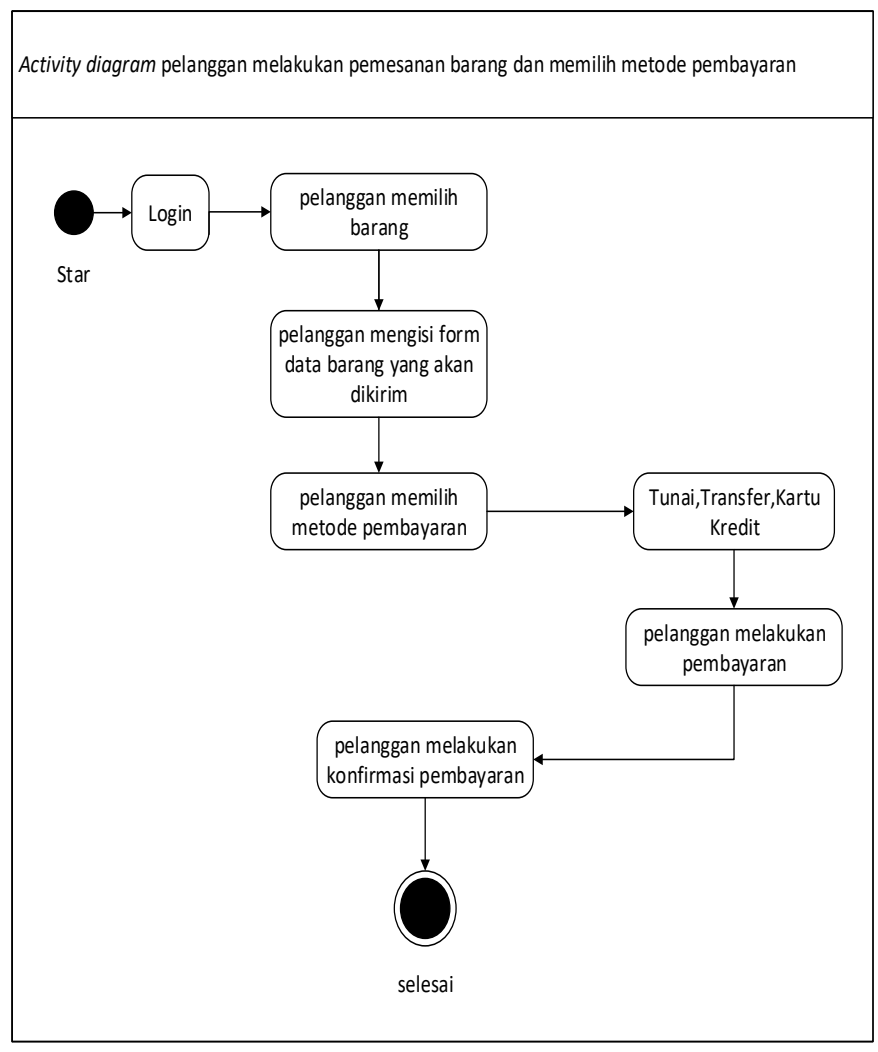

Gambar 3. Activity Diagram Pelanggan Melakukan Pemesanan dan Metode Pembayaran

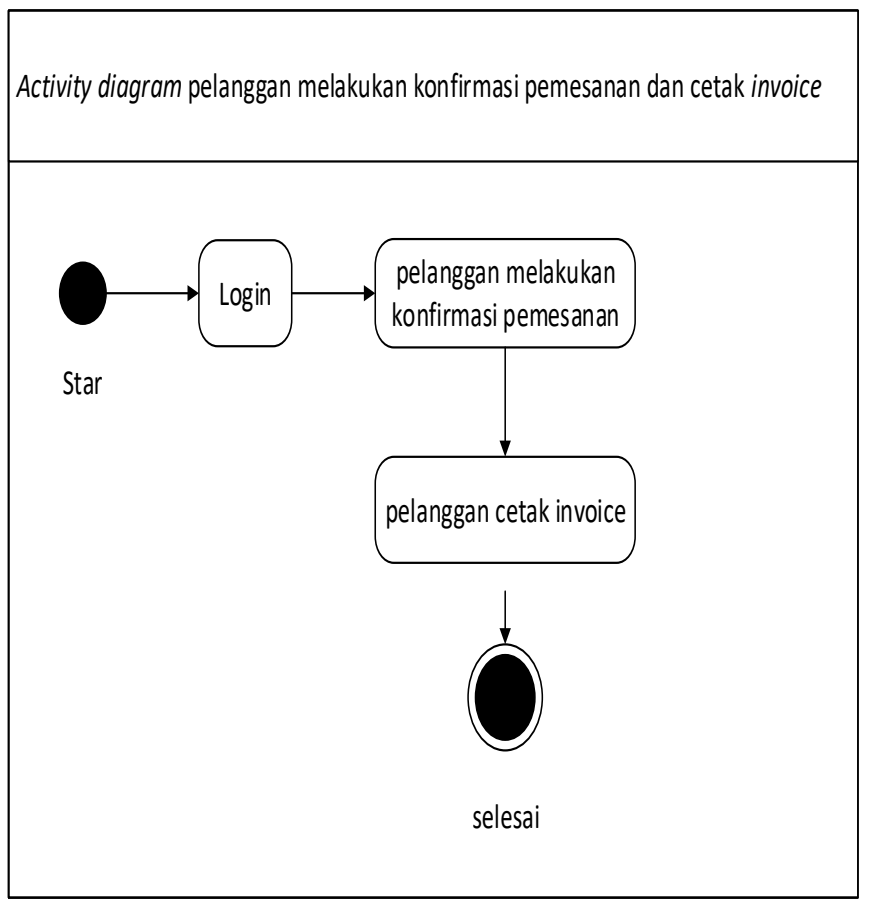

Gambar 4. Activity Diagram Pelanggan melakukan konfirmasi pemesanan dan cetak invoice pemesanan 


\section{IMPLEMENTASI SISTEM}

Pembuatan website dengan menggunakan Macromedia Dremaweaver 8 sebelum website tersebut di hosting ke jaringan internet. Berikut ini adalah rancangan website penjualan old book secara online menggunakan Macromedia Dreamweaver 8:

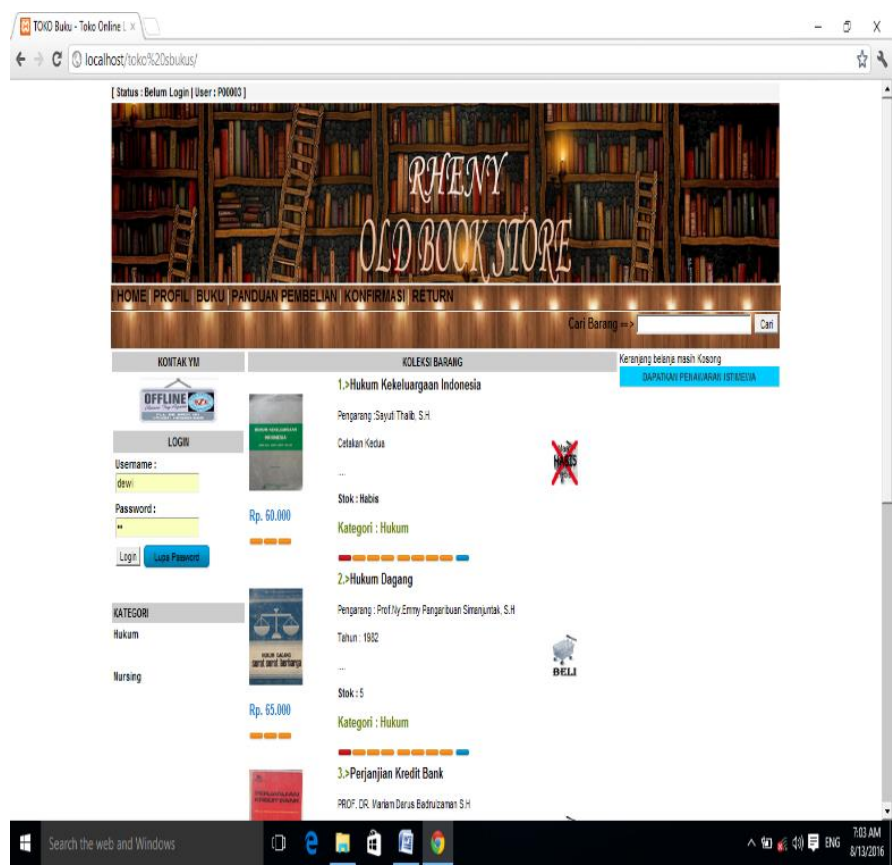

Gambar 5. Halaman Utama Pelanggan

Pada halaman utama pelanggan ini dapat melihat dan mengakses menu-menu utama website seperti profil, kategori buku, jadwal, panduan pembelian, konfirmasi, retur, cari buku, logout.

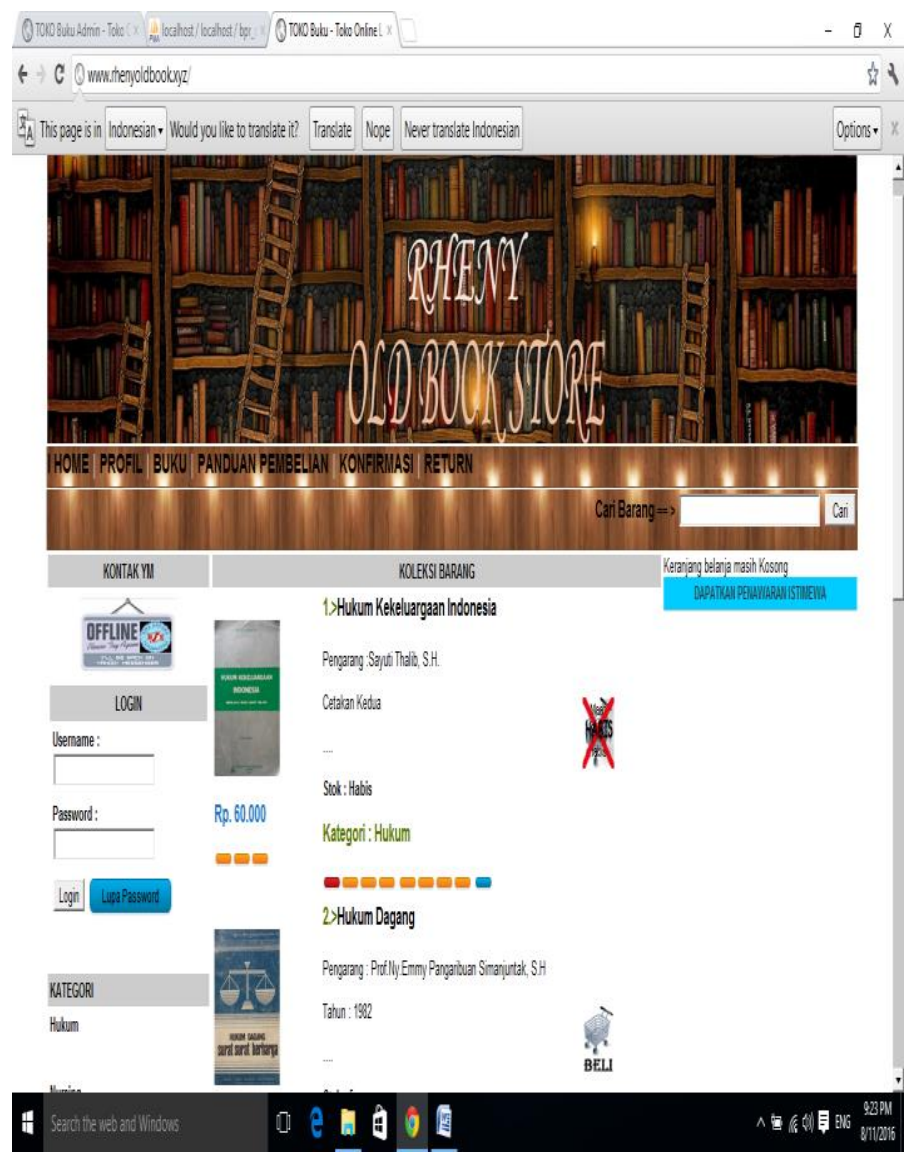

Gambar 6. Halaman login Pelanggan

Pelanggan dapat melakukan pemesanan tanpa harus melakukan login terlebih dahulu, apabila pelanggan sudah melakukan pendaftaran maka harus melakukan login terlebih dahulu dengan memasukan username dan password yang sudah dimiliki.

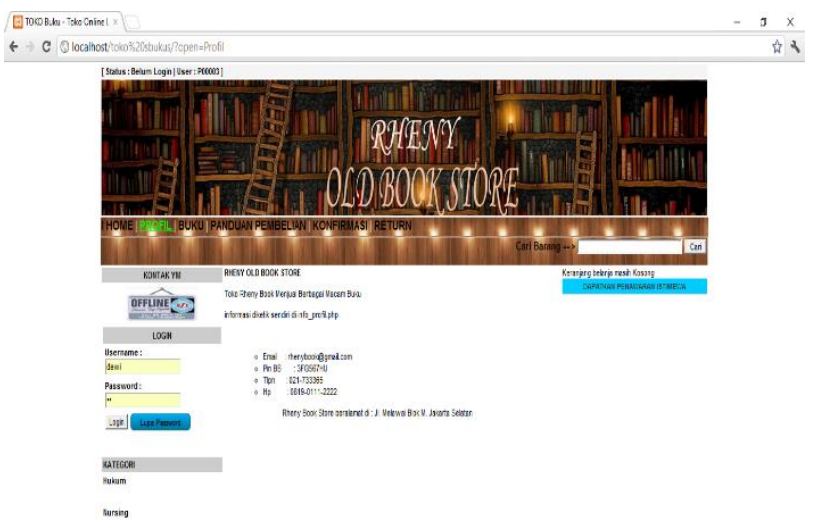

4

Gambar 7. Halaman Menu Profil 
Pelanggan dapat melihat menu profil rheny book dan bisa mengetaui alamat toko rheny book serta dapat menghubungi di nomor telpon yang sudah tersedia.

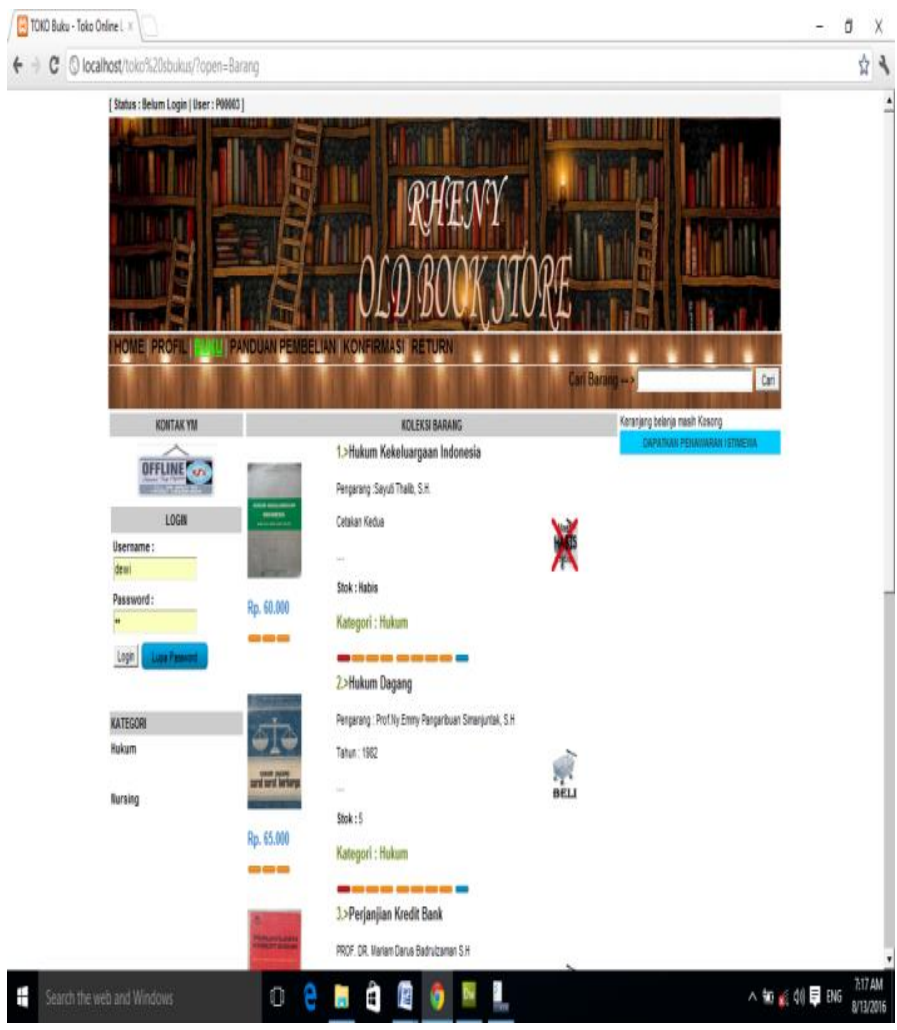

Gambar 8. Halaman Menu Kategori Buku
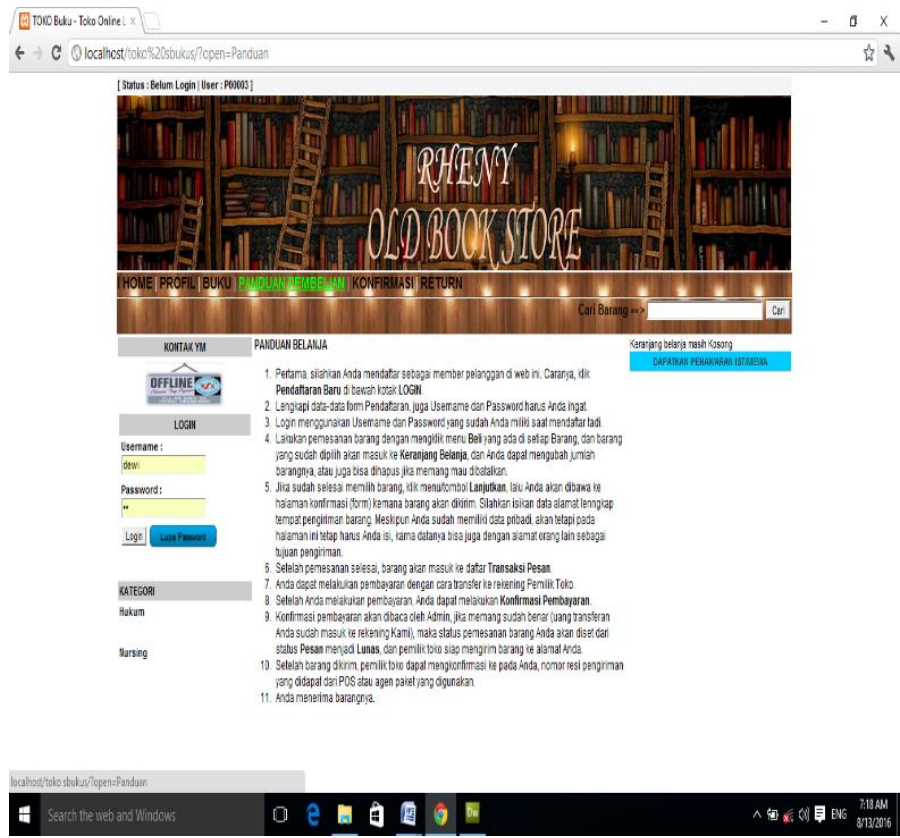

Sebelum melakukan pemesanan, pelanggan disarankan untuk membaca terlebih dahulu panduan pembelanjaan supaya memudahkan pelanggan dalam melakukan pemesanan dan transaksi.

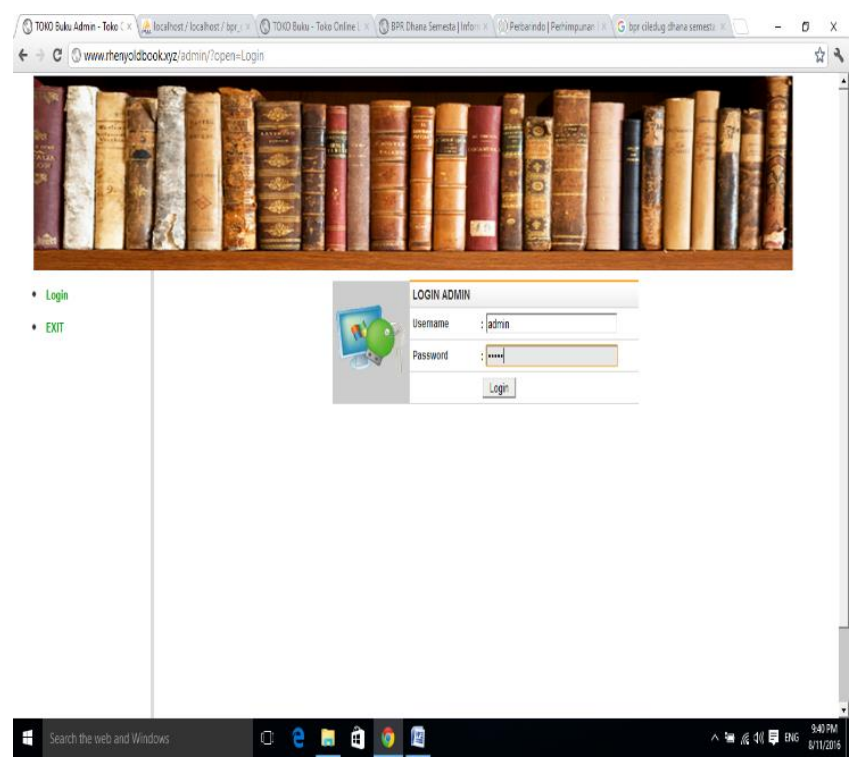

Gambar 10. Halaman Login Admin

Halaman login admin berisi form login yang di isi oleh admin, pada halaman ini admin mengisi username dan password yang sudah terdaftar. Jika admin sudah selesai menginput username dan password maka admin dapat memilih tombol login untuk bisa mengakses halaman admin.

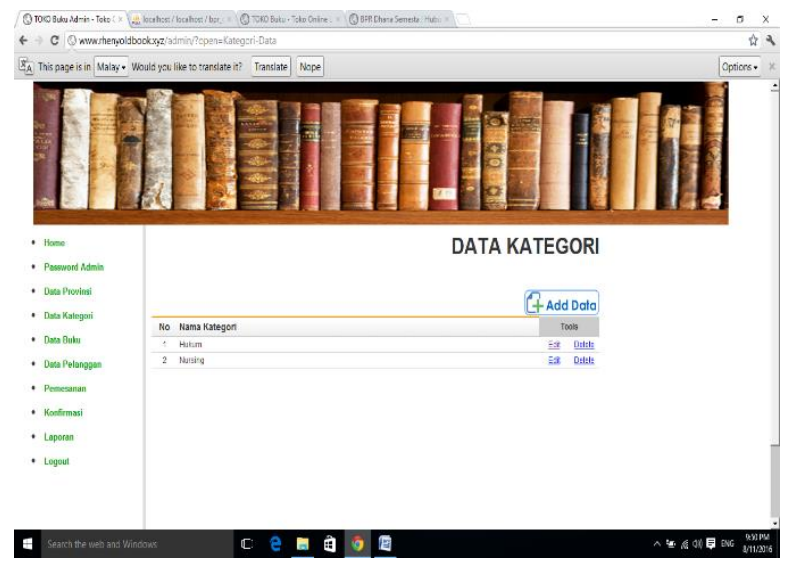

Gambar 11. Halaman Menu Utama Data Kategori

Admin dapat menambahkan dan menghapus data kategori buku.serta mengedit data buku.

Gambar 9. Halaman Login Pelanggan 


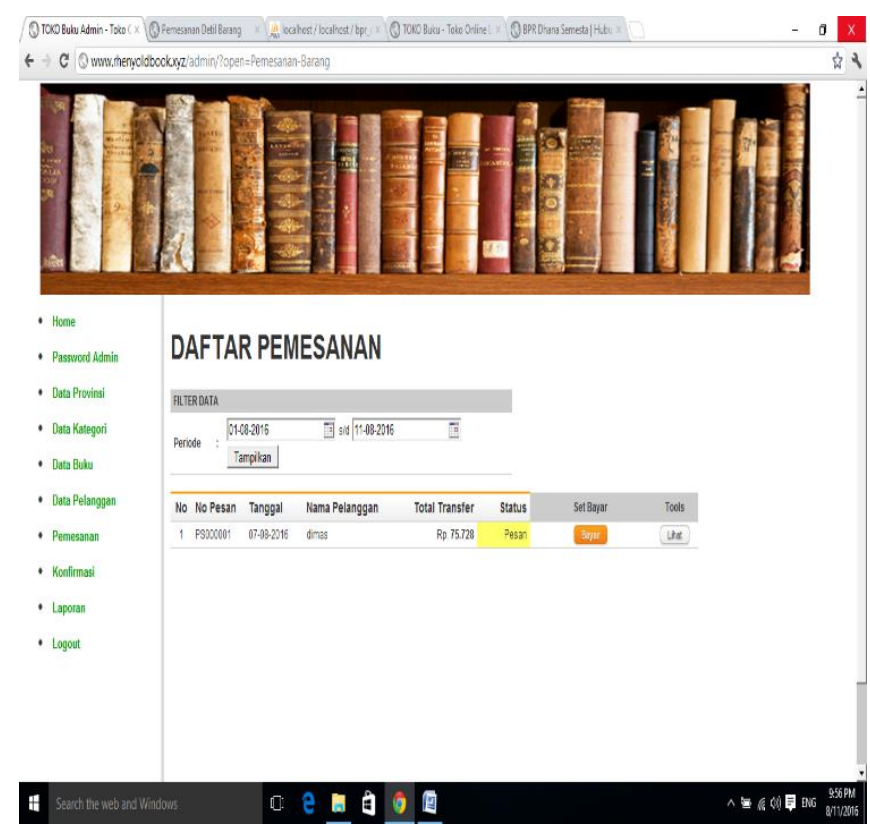

Gambar 12. Halaman Utama Daftar Pemesanan

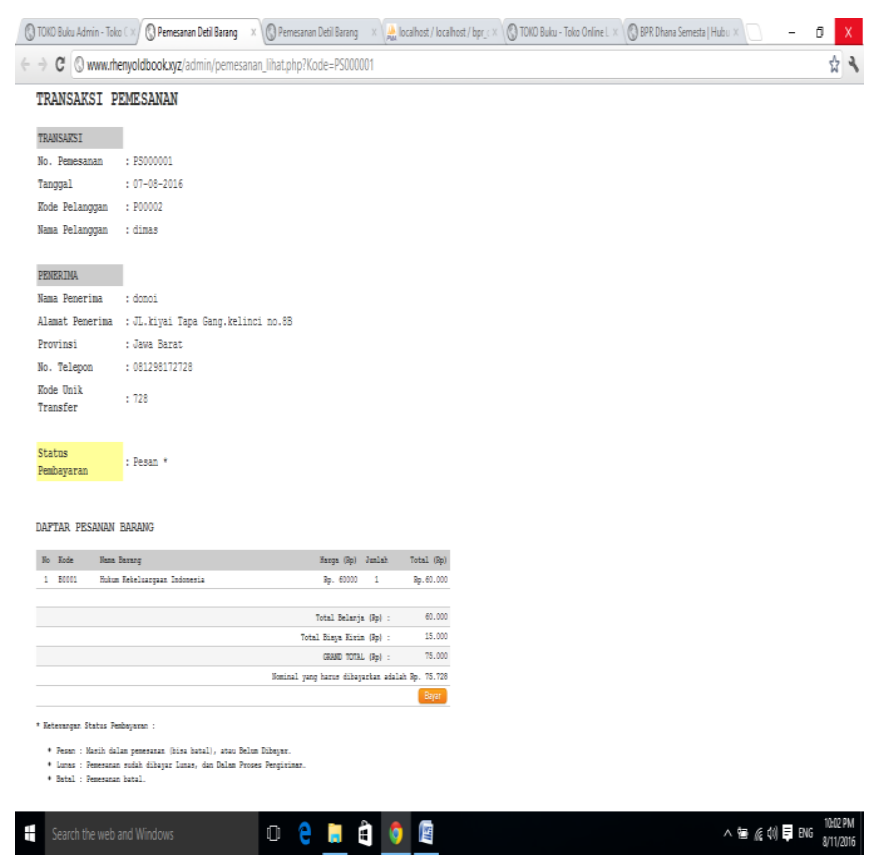

Gambar 13. Halaman Menu Transaksi Pemesanan

\section{KESIMPULAN}

Sistem Informasi penjualan old book secara online pada toko Rheny Book merupakan pengembangan dari sistem yang sedang berjalan. Berbagai permasalahan yang muncul telah diupayakan untuk dapat ditangani dengan sistem baru yang diusulkan ini. Adapun kesimpulan yang dapat diambil dari pembangunan sistem informasi penjualan old book secara online ini antara lain:

1. Dengan dibuatnya penjualan secara online ini, calon pelanggan baru dapat dengan mudah melihat informasi mengenai old book terlaris.

2. Dengan adanya penjualan secara online ini dapat meningkatkan efektifitas dan efisien dari segi tenaga, waktu dan biaya.

3. Pelanggan juga dapat melakukan konfirmasi pembayaran secara langsung dari website ini karena tersedia form konfirmasi pembayaran.

4. Apabila username ataupun password salah, ataupun kedua nya salah maka pelanggan tersebut tidak dapat melakukan login. Jika username dan password yang dimasukan kosong, maka pelanggan tersebut tidak dapat melakukan login. Jika username dan password yang dimasukan oleh pelanggan tersebut benar, maka member tersebut dapat melakukan login dan melakukan pemesanan barang.

5. Pelanggan member dapat Melihat History pemesanan yang pernah mereka pesan.

6. Pelanggan dapat melakukan konfirmasi pembayaran via website

7. Admin harus melakukan login terlebih dahulu untuk dapat mengakses menu atau halaman admin. Apabila username ataupun password salah, ataupun kedua nya salah maka admin tersebut tidak bisa memasuki. atau mengakses menu atau halaman admin. Jika username dan password atau salah satunya admin kosong, maka admin tersebut dapat memasuki atau mengakses menu atau tampilan admin. Jika username dan password yang dimasukan oleh admin tersebut benar, maka admin tersebut dapat memasuki atau mengakses menu atau tampilan admin.

8. Admin dapat mengelola data kategori, data provinsi, seperti mengedit, mengubah atau menghapus. Admin dapat membuat laporan data pemesanan.

9. Metode pembayaran hanya bisa dilakukan dengan Transfer ke rekening Rheny Book. Dan pelanggan harus melakukan konfirmasi pembayaran via website.

10. Dengan dibuatnya Sistem Informasi Penjualan Old Book Secara Online diharapkan dapat mendukung kinerja serta para pelanggan lebih mengetahui lagi tentang old book.

\section{SARAN-SARAN}

Berdasarkan kesimpulan diatas, maka penulis memberikan saran-saran yaitu sebagai berikut: 
1. Perlu adanya penyempurnaan fungsi dan link agar lebih mempermudah pengunjung untuk melihat informasi web terbaru.

2. Perlu ditingkatkan kembali untuk maintenanance web agar lebih banyak mengupdate hal-hal yang berkaitan dengan old book.

3. Mengingat pentingnya data yang tersimpan dalam file maka perlu dibuat back up file.

4. Melihat perkembangan internet yang semakin pesat, maka website juga harus selalu ada perkembangan dengan baik dari segi tampilan.

\section{DAFTAR PUSTAKA}

Ariyantantina,2014. Sistem Informasi Pembelian dan Penjualan Buku Secara Multiuser.ISSN : 23384018 Jurnal Tikomsin, 2014:2338-4018

Fathansyah. 2012. Basis Data. Bandung: Informatika Bandung.

Firdaus. 2007. 7 Jam Belajar Interaktif PHP dan MySQL dengan Dreamweaver. Palembang: Maxikom.

Frieyadie. 2007. Belajar Sendiri Pemrograman Database Menggunakan Foxpro 9. Jakarta: PT. Elex Media Komputindo.

Gozali,2012. Perancangan SIstem Informasi Penjualan Buku Pada PD. Restu Percetakan.ISSN : 23027339 PelitaInformatika Budi Darma, Volume:VII, No.2, Agustus 2014:2301-9425.

Kusrini,Koniyo,2007.Tuntunan Praktis Membangun Sistem Informasi Dengan Visual Basic \& Microsoft SQL Server, Yogyakarta: CV. Andi Offset.

Ramadhan. 2006. Students Guide Series: Pemprograman Web Database dengan PHP dan MySQL. Jakarta: PT. Elex Media Komputindo.

Sitorus,2014. Sistem Informasi Penjualan Buku Berbasis Web Menggunakan Model View Controller(MVC) (Studi Kasus Toko Buku Naga Timbu Pakam). ISSN : 2301-9425 Jurnal Algoritma Sekola Tinggi Teknologi Garut, Vol.09, No.25, 2012:2302-7339. 